\title{
Non-Puerperal Uterine Inversion with Uterine Mülleroblastoma in a Teenager: A Case Report of Loandjili General Hospital Pointe-Noire (Republic Of Congo)
}

\author{
L. M. E. Eouani1,2, J. C. Mokoko2,3, Ngatali Sidney²,4, A. Emeka Pognabeka1, C. Itoua5 , L. H. Iloki2,3 \\ ${ }^{1}$ Obstetrics Gynecology Service, Loandjili General Hospital, Pointe Noire, Congo \\ ${ }^{2}$ Faculty of Health Sciences, Marien Ngouabi University, Brazzaville, Congo \\ ${ }^{3}$ Obstetrics Gynecology Service, University Health Center of Brazzaville, Brazzaville, Congo \\ ${ }^{4}$ Department of Cancerology, Loandjili General Hospital, Pointe Noire, Congo \\ ${ }^{5}$ Department of Obstetric Gynaecology, Teaching Hospital of Brazzaville, Brazzaville, Congo \\ Email: *eouani@yahoo.fr
}

How to cite this paper: Eouani, L.M.E., Mokoko, J.C., Sidney, N., Emeka Pognabeka, A., Itoua, C. and Iloki, L.H. (2020) Non-Puerperal Uterine Inversion with Uterine Mülleroblastoma in a Teenager: A Case Report of Loandjili General Hospital Pointe-Noire (Republic Of Congo). Open Journal of Obstetrics and Gynecology, 10, 723-728.

https://doi.org/10.4236/ojog.2020.1050066

Received: February 7, 2020

Accepted: May 10, 2020

Published: May 13, 2020

Copyright (C) 2020 by author(s) and Scientific Research Publishing Inc. This work is licensed under the Creative Commons Attribution International License (CC BY 4.0).

http://creativecommons.org/licenses/by/4.0/

cc (i) Open Access

\begin{abstract}
Introduction: Uterine inversion is a reversal of the uterus into a glove. It is an obstetric complication of deliverance. Uterine inversion out from pregnancy is rare. The Müller duct is an embryonic tubular formation which will transform into the vagina, uterus, and fallopian tubes. The mixed Müllerian malignant tumor is a rare tumor to girl and woman in genital activity, which develops in the uterus at the expense of vestige of the Müller channels. The association of these two pathologies is rare. We report an observation of complicated uterine inversion mulloblastoma to a teenager. Observation: A teenager of 15 years old, admitted for a vulvar tumor, which has occurred about two months. Student in the first class of senior high school, she has no medical history, and no particular surgery. She had her threat at the age of 13 , and has a regular menstrual cycle of 30 days, with 05 days of period. Two months before her admission, the patient noticed during her menstruation, the perception of soft intravaginal tissue but which disappeared when her period stopped. A week before her admission, she felt pelvic pain with expulsive colic, radiating to the external genitals, 3 days later, a protusion from the vaginal vestibule of a mass, so the volume gradually increased. It is in front of this situation that the patient consults a health center, which refers her to us for treatment. On admission, the patient was conscious with a good hemodynamic state. Vulva inspection revealed a large, rounded mass with an endovaginal implantation, with necrosis areas. This mass was resistant, bleeding in any manipulation, mobile, perceive neither the cervical relief nor the pres-
\end{abstract}


ence of the uterus. The ultrasound assessment had marked: a large abdomino-pelvic pseudo-mass with urinary repercussions right form of hydronephrosis uretero and associated with gastric distension, and MRI complete inversion of the uterus, with the uterine in the vaginal cavity associated with a large vulvovaginal mass. An apathetic examination of the specimen had made it possible to diagnose a botryoid sarcoma that affects the cervix and uterine body (Mullerian tumor). Laparotomy had revealed uterine inversion. This required a total hysterectomy with appendectectomy had been performed. Then the patient was transferred to the cancer service for treatment where in the seventh day, she died in the surgery post.

\section{Keywords}

Metrorrhagia, Swelling, Uterine Inversion, Medulloblastoma

\section{Introduction}

Uterine inversion is a reversal of uterus with glove finger [1]. It is an obstetric complication of deliverance [2]. It occurs outside of pregnancy and it is rare.

The causes found in the non-puerperal context are, uterine fibroids, and uterine hypoplasia [1]. The Müller channel is a tubular formation, embryonic which will transform to the woman into vagina, uterus, and fallopian tubes. Müllerian mixed malignancy is a rare tumor to the girl and the woman in genital activity, which is developed in uterus, depends on the Müller canal vestige. The association of both pathologies is rare. We report an observation to the complicated uterine inversion mulloblastoma to a teenager.

\section{Observation}

It is a teenager of 15 years old, admitted for a large vulvar tumor, it happened two months ago. She is in the first level of high school, she has no medical history, and no particular surgery. She was 13 years old, she had her threat, and has a regular 30-day menstrual cycle, with 05 days of periods. Two months before her admission, during her period, the patient noticed the perception of intravaginal soft tissue but which disappeared when the period stopped. A week before her admission, she had pelvic pain of expulsive colic, radiating to the external ginitaus, 3 days later, a protusion through the vaginal vestibule of a mass, so the volume increased progressively, vis-à-vis to that situation, the patient consults a health center, which lead us to the pick-up charge.

At the admission, the patient was conscious with a good state of hemodynamic .vulva inspection lead us to discover a large mass, and endovaginal implantation, with areas of necrosis (Figure 1). This mass was firm and bleeding in all manipulation, the case does not allow to perceive the cervical relief or the presence of uterus. The ultrasound assessment had marked: a large abdomino-pelvic pseudo-mass with urinary resounding in the form of a right hydronephrosis uretero and associated with gastric distension (Figure 2), and on MRI a complete 


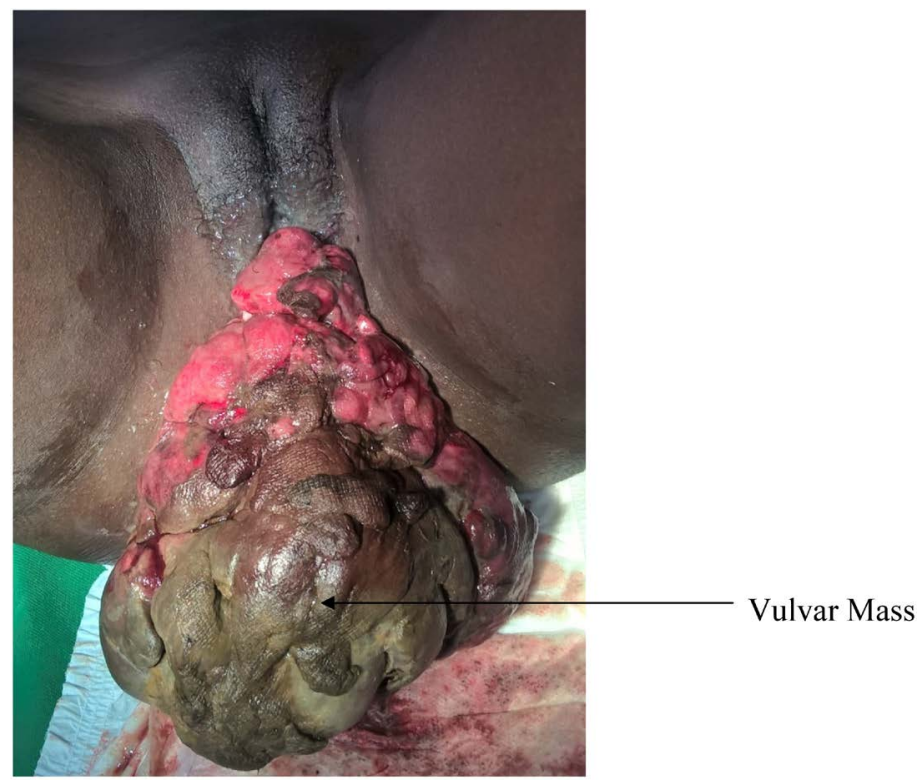

Figure 1. Vulvar mass.

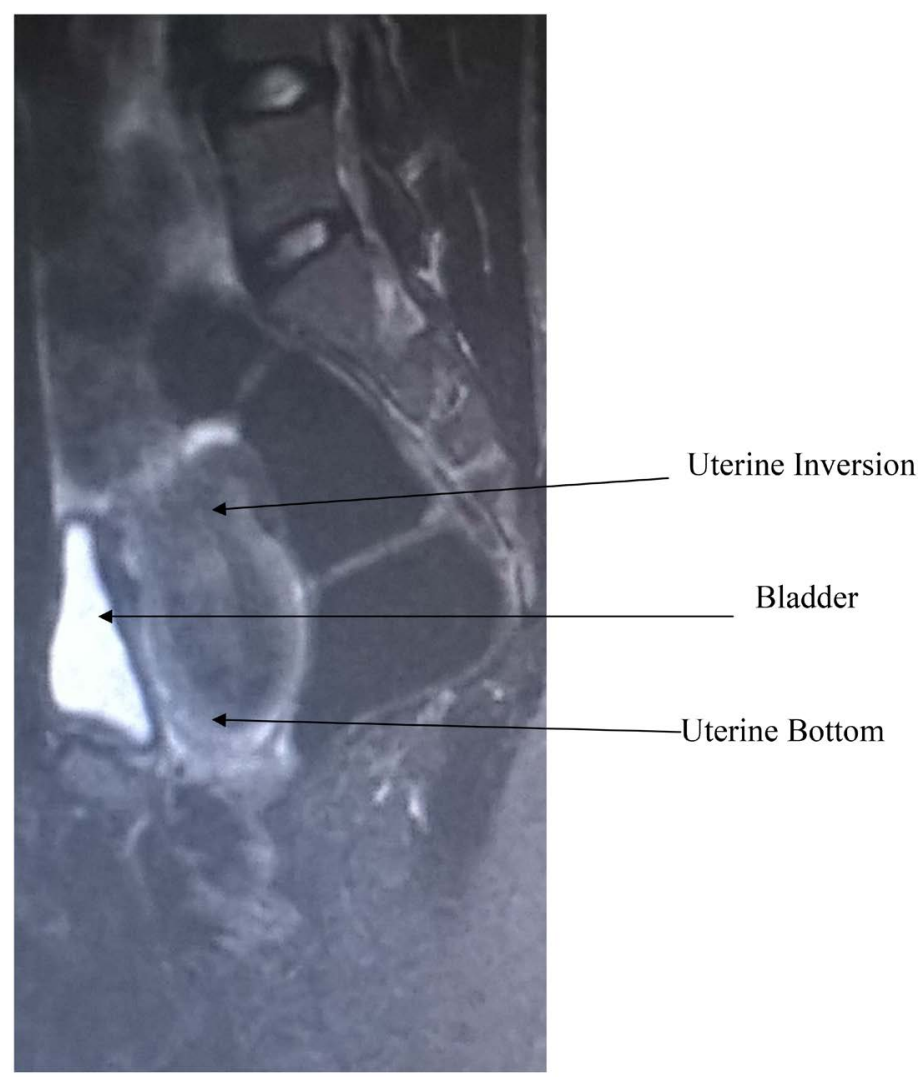

Figure 2. Utérine inversion at MRI.

inversion of the uterus, with the uterine bottom in the vaginal cavity associated with a large vulvovaginal mass (Figure 3). Anapathic examination of the sample part allowed to diagnose a botryoid sarcoma that affects the cervix and uterine body (Mullerian tumor). 


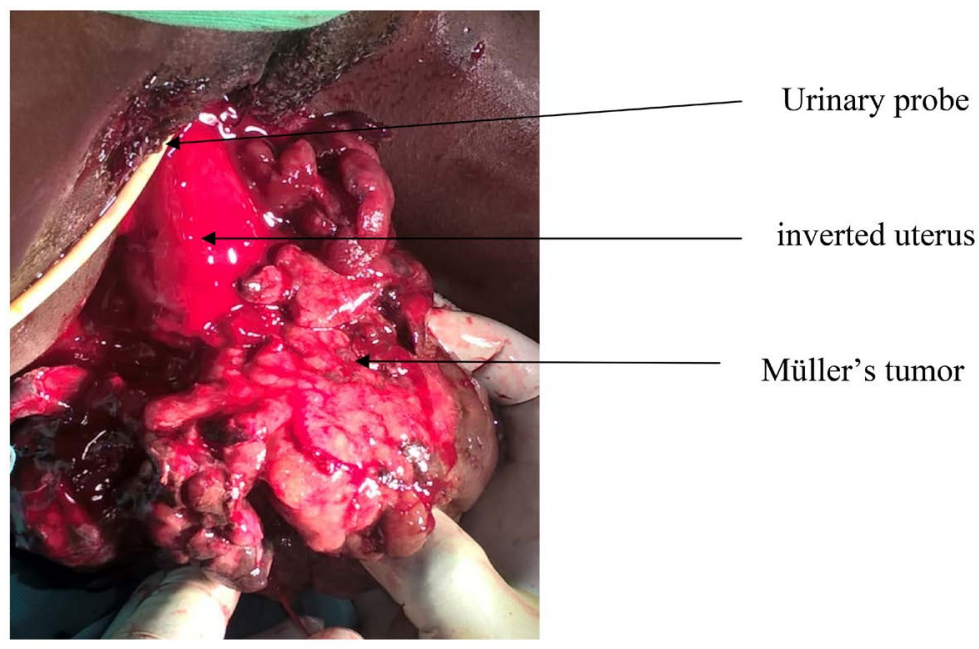

Figure 3. Uterine inversion.

Laparotomy had revealed uterine inversion. It needs a hysterectomy and appendectectomy had been performed.

The patient was sent to the Cancer-ology department for a picking-up charge but the seventh day of the sugary, she died.

\section{Discussion}

Muller's tumors as well as uterine inversion in the non-puerperal period are rare, which is developed through female genital tract. It is common in black women compared to white women [3]. One of the major signs in both cases is genital bleeding [1] [4].

In the year, rhabdomyosarcomas in children is 4.3 per million children [4]. These are the most common muscle-differentiating tumors of the soft tissue. They represent $4 \%$ to $6 \%$ of solid malignant tumors in children and $60 \%$ to $70 \%$ of all soft tissue sarcomas [3] [5].

After localization towards the head and neck, the urogenital sphere comes in the $2^{\text {nd }}$ position and has about $22 \%$ of rhabdomyosarcomas [4] [6].

A kind of anatomopathological is found in that last localization. It is the botryoid, named because of the cluster aspect of that tumor. The term botryoid was last used by Pfannestiel in 1892 [2]. That method is exclusively used to children. It seems that tumor to children is more common in boys than girls with a sex ratio at 1.5 [7].

Regarding signs, the clinical board is dominated by capricious vaginal bleeding, recurrent and sometimes abundant and bleeding in case of intra uterine localization.

In the case of macroscopic, the aspect found is usually a dense tumor, firm, sometimes encephaloid, simply necrotic and hemorrhagic [3]. If reached bladder injury, a lesion assessment will permit a biopsy; an intravenous urography can study the renal impact.

Histologically, several classifications have been proposed. Among them, the 
one which shows 4 histological types of rhabdomyosarcomas: botryoid, embryonic, alveolar, polymorphic. Half of the cases are diagnosed during the first ten years of life. However, it exist two kinds of frequencies between 2 and 6 years old and between 15 and 19 years old. The most known is embryonic rhabdomyosarcoma; it represents $50 \%$ to $60 \%$ of all rhabdomyosarcomas. Botryoid Rhabdomyosarcoma is a variant of the embryonic; represents $5 \%-10 \%$ of all rhabdomyo-sarcoma. The treatment of rhabdomyosarcomas combines radiotherapy surgery and chemotherapy [6]. Surgery consists of an anatomical castration. The concept chemotherapy was included in 1960. It is about three combinations with vincristine, actinomycin and cyclophosphamid (VAC) [8]. Operated rhabdomyosaromas must be looked after monitoring because the patients are not sheltered [4]. That tumor spreads very quickly, gradually reaching the neighboring organs and bones by contiguity. Lymphatic invasion is more common in rhabdomyosarcomas to the lower limbs and to urinary organs [1].

Surgery and radiotherapy are combined to provide the best local gesture essential for healing. Chemotherapy makes it possible to act locally and to the distance by preventing the appearance of metastases. The combination of vincristine, actinomycin, cyclophosphamide (VAC) it has demonstrated its effectiveness.

The use of chemotherapy combined with radiotherapy has transformed the prognosis of these tumors. The survival of 3 years, which was $10 \%$ to $15 \%$ in 1960 , nowadays has increased to $70 \%$ today [2].

\section{Conclusions}

Botryoid rhabdomyosarcomas of the urogenital tract are malignant lesions rare and less known, they are found to the children. The picking-up charge has been improved by the surgery association, radiotherapy and chemotherapy. For low-income countries, early diagnostic remains essential in picking-up charge of patients.

The prognostic is not really clear despite the therapeutic improvement of these last years.

\section{Conflicts of Interest}

The authors declare no conflicts of interest regarding the publication of this paper.

\section{References}

[1] Eouani, L.M.E., Itoua, C., Nzengomona Milandou, L.V., Emeka Pognabeka, A. and Iloki, L.H. (2016) Uterine Inversion: About One Case at Loandjili General Hospital of Pointe-Noire. Black African Medicine, 63, 71-75.

[2] Slaoui, M.A., Bouchikhi, C. and Banani, A. (2010) Puerperal Uterine Inversion. Revue médicale de Liège, 65, 510-513.

[3] Prasmit, A.S., Vikas, S.S., Prakash, M.R., Sudhamani, S. and Bhalekar (2016) Malignant Mixed Mulleriantumor: A Rare Case Report. AMHS, 4, 105-108. 
https://doi.org/10.4103/2321-4848.183339

[4] Tekwani, D.T., Joshi, S.R., Pathak, S., Nagare, M., Bihade, A. and Kendre, D. (2013) Malignant Mixed Mulleriantumor of the Uterus: A Case Report. Indian Journal of Basic and Applied Medical Research, 3, 33-36.

[5] Barani, K. and Padmavathi, R. (2013) Two Rare Cases of Malignant Mixed Mulleriantumor. The Internet Journal of Pathology, 15, 1-8.

[6] Thawal, Y.A., Tambe, S.G., Tania, A., Chavan, R.R. and Patel, J.A. (2014) A Rare Case of Malignant Mixed Mulleriantumour of Uterine Corpus. International Journal of Current Medical And Applied Sciences, 3, 100-102.

[7] Siva, R.D., Surendar, J., Rama, A.S. and Manjunatha, H.K. (2013) Malignant Mixed Mulleriantumor of the Uterus (Uterine Carcinosarcoma): A Case Report. IOSR Journal of Pharmacy, 3, 49-52. https://doi.org/10.9790/3013-0309-49-52

[8] Lee, T.Y., Lee, C., Choi, W.J., Lee, J.Y. and Kim, H.Y. (2013) Synchronous Occurrence of Primarymalignant Mixed Mülleriantumor in Ovary and Uterus. Obstetrics \& Gynecology Science, 56, 269-272. https://doi.org/10.5468/ogs.2013.56.4.269 